\title{
What is the Diagnosis?
}

\section{CASE PRESENTATION}

\section{Pre-syncope during pacemaker follow-up}

An 83-year-old female implanted a dual-chamber pacemaker (Adapta DR) one year before threating a sinus node disease with symptomatic sinus arrest (up to $4.2 \mathrm{~s}$ ). In the last month, the patient complained of palpitation and dizziness. She has a previous history of hypertension and nondialytic chronic renal failure. The long-term medical therapy consisted daily of losartan $100 \mathrm{mg}$, atorvastatin $10 \mathrm{mg}$ and aspirin $100 \mathrm{mg}$. Pacemaker telemetry showed a $90 \%$ battery, normal function of pacing leads and short episodes of atrial fibrillation. Statistical pacing was $92 \%$ in the atrium and $26 \%$ in the ventricle. The pacemaker was programmed in managed ventricular pacing (MVP) mode with sensor (AAIR and DDDR) and basic heart rate of $65 \mathrm{cpm}$. A 24 h-Holter monitoring was used in the investigation (Fig. 1). What is the mechanism?

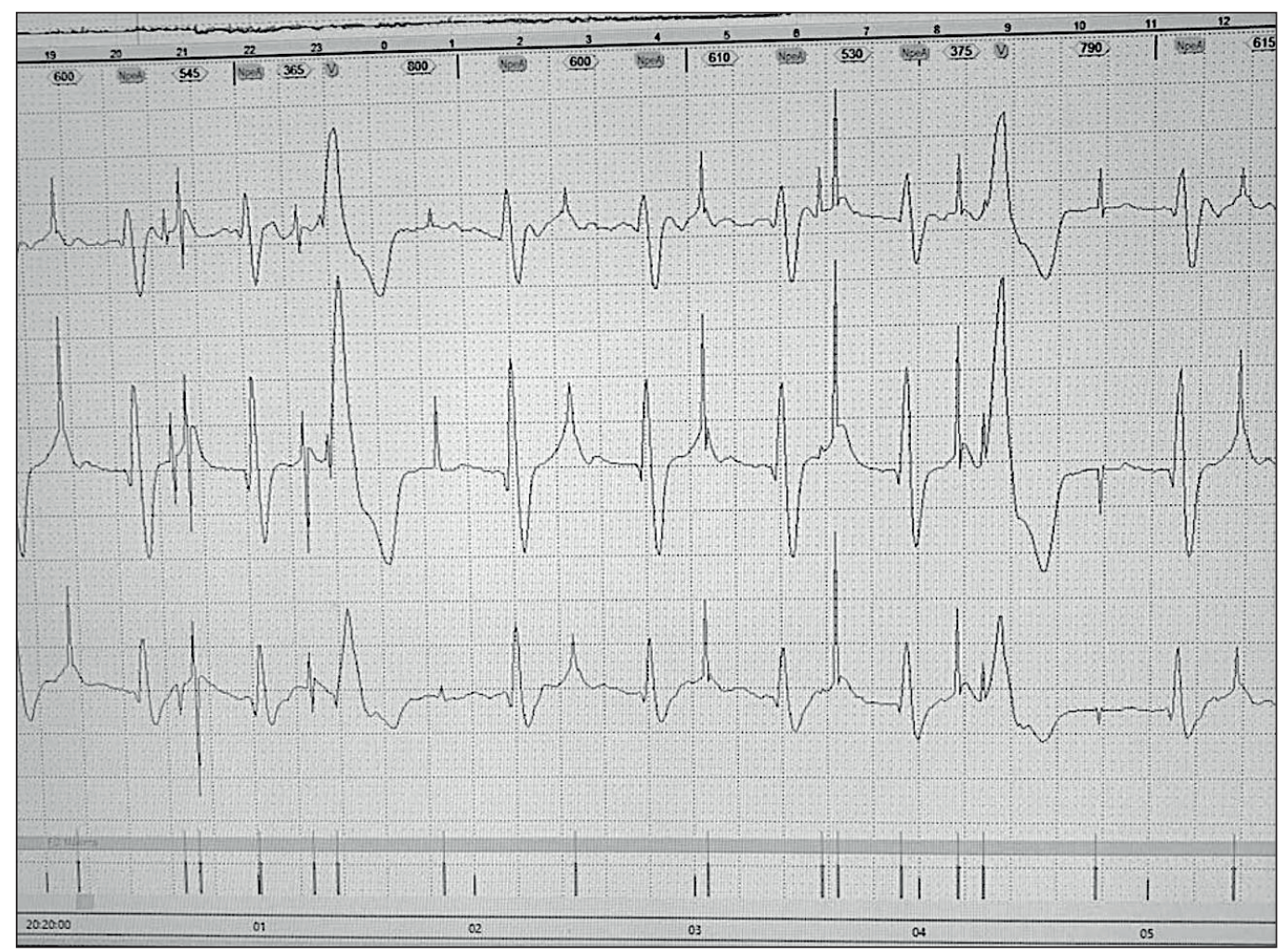

Figure 1. ECG was recorded during moderate efforts with complain of dizziness and palpitation. 


\section{ANSWER}

Initial analysis of ECG (Fig. 1) may be suggesting some dysfunction of pacemaker. However, careful inspection of track can help the diagnosis. In Fig. 2, MVP function was adequately activated with two different moments of DDDR and AAIR pacing at cycle of $750 \mathrm{~ms}$. Briefly, the MVP mode is an atrial-based pacing mode designed to promote intrinsic conduction and to reduce the percentage of unnecessary right ventricular pacing. Managed ventricular pacing provides the following functions: AAI mode pacing when AV conduction is intact.

Figure 3 presents a schematic explanation of the functional findings of the pacemaker. The ECG recorded during 24 h-Holter showed some aspects of functionality of dual-chamber pacemaker: 1) atrial pacing guided by sensor during patient movement; 2) MVP promoting a preferential intrinsic atrioventricular conduction; 3) safety paced episodes due to crosstalk; and 4) functional ventricular refractoriness of pacemaker. After adjusting the pacemaker mode (DDDR), atrial sensibility and changing in the form of stimulation of both chambers (from unipolar to bipolar), the symptoms were completely resolved; and a $24 \mathrm{~h}$-Holter monitoring showed a regular paced rhythm.

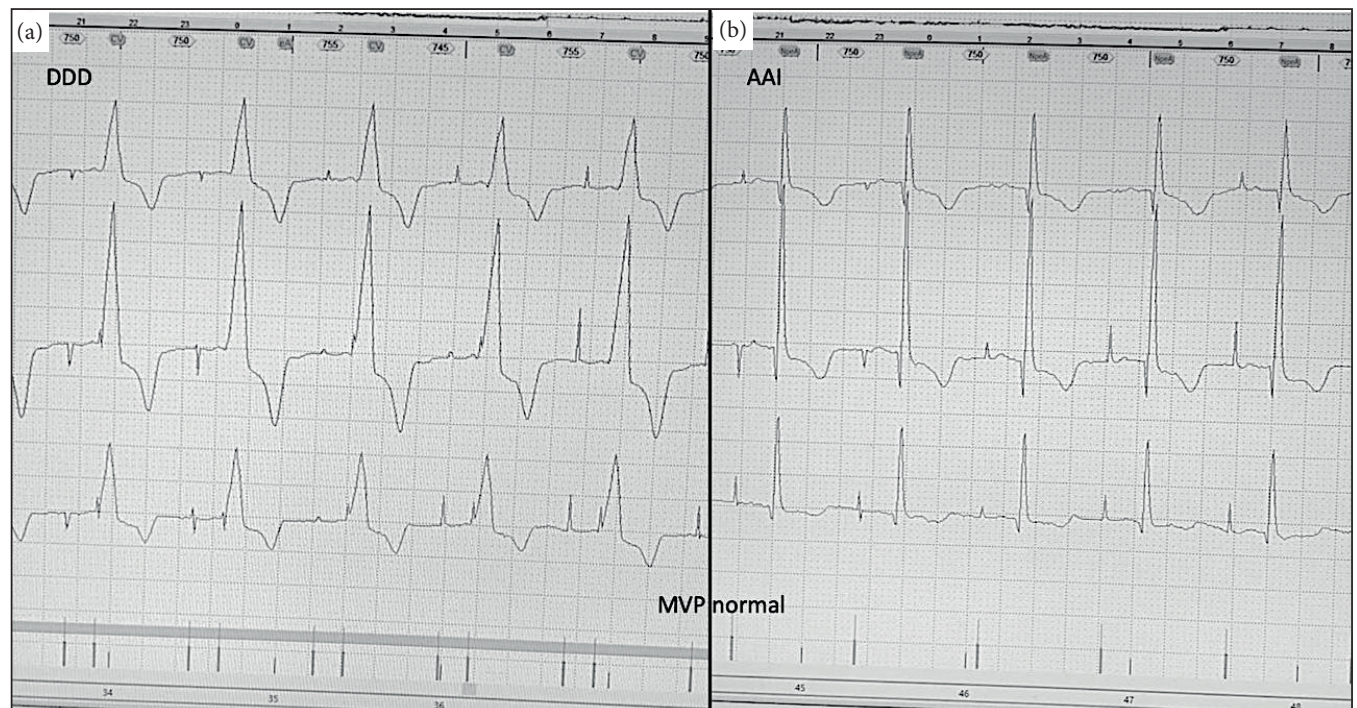

Figure 2. Different asymptomatic moments of MVP functionality during 24 h-Holter monitoring: (a) DDD mode and (b) AAI mode.

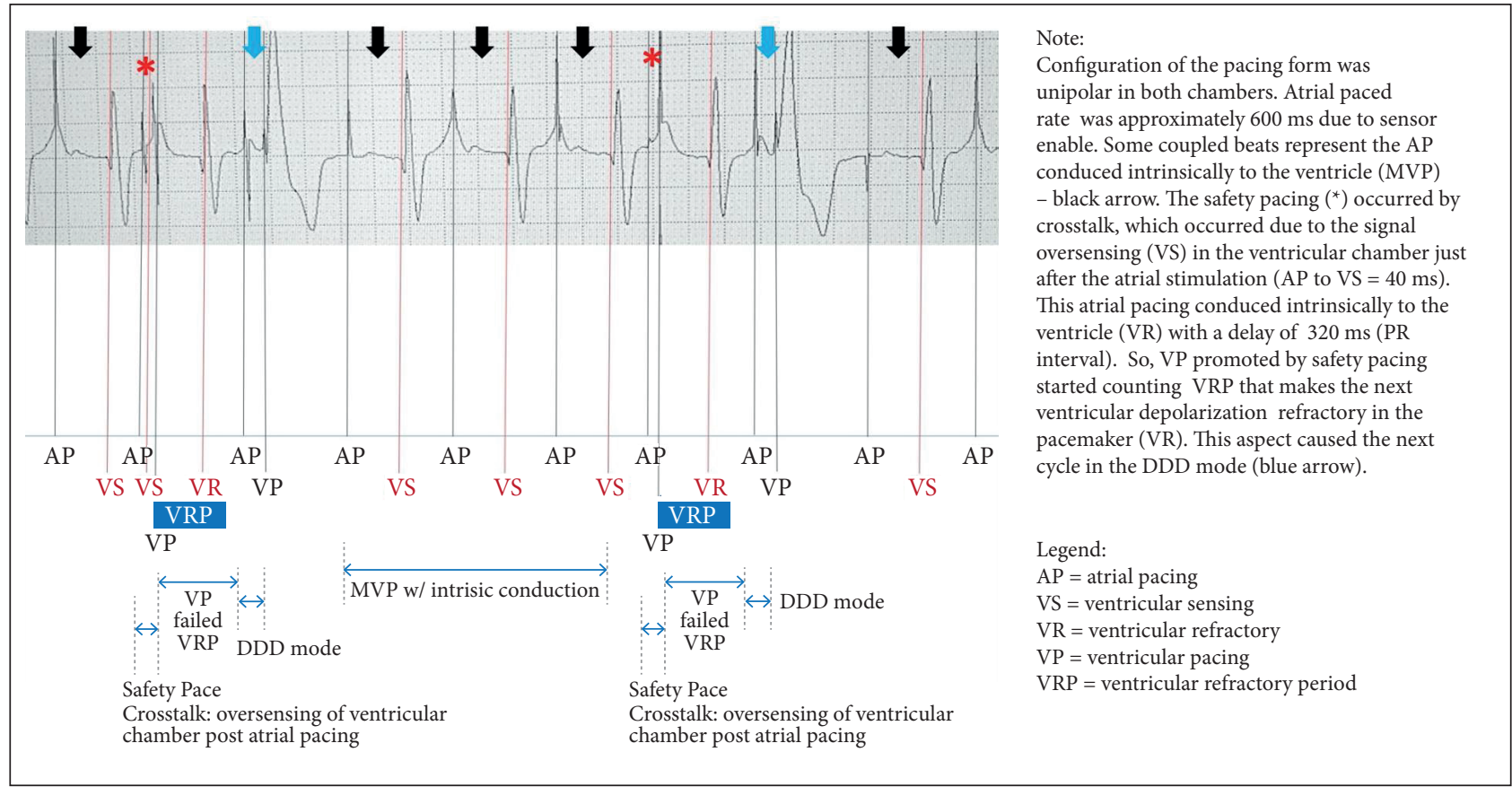

Figure 3. Schematic representation of ECG recorded during symptomatic event. 


\section{REFERENCE}

1. Ellenbogen K, Wilkoff B, Kay GN, Lau CP, Auricchio A. Clinical cardiac pacing, defibrillation and resynchronization therapy. 5th ed. Philadelphia: Elsevier; 2016.

\section{AUTHOR}

\section{Cristiano de Oliveira Dietrich ${ }^{1, *}$}

Dietrich CO (D) https://orcid.org/0000-0002-7373-9119

1.Centro de Arritmias e Eletrofisiologia Cardíaca - São Paulo (SP), Brazil.

*Correspondence author: centrodearritmias@gmail.com 